\title{
Influences of True Triaxial Loading-Unloading Stress Paths on Mechanical Properties and Wave Velocity of Coal Samples subject to Risk of Rock Burst
}

\author{
Wei Shen $\mathbb{D}^{1},{ }^{1,2}$ Guang-Jian Liu $\mathbb{D}^{2},{ }^{2}$ Lin-Ming Dou $\mathbb{D}^{1},{ }^{3}$ Si-Yuan Gong, ${ }^{4}$ and $\mathrm{Hu} \mathrm{He}^{5}$ \\ ${ }^{1}$ Faculty of Architecture and Civil Engineering, Huaiyin Institute of Technology, Huai'an, Jiangsu 223001, China \\ ${ }^{2}$ Key Laboratory of Rock Mechanics and Geohazards of Zhejiang Province, Shaoxing University, Shaoxing, \\ Zhejiang 312000, China \\ ${ }^{3}$ School of Mines, Key Laboratory of Deep Coal Resource Mining, Ministry of Education, \\ China University of Mining and Technology, Xuzhou, Jiangsu 221116, China \\ ${ }^{4}$ School of Mines, Jiangsu Engineering Laboratory of Mine Earthquake Monitoring and Prevention, \\ China University of Mining and Technology, Xuzhou, Jiangsu 221116, China \\ ${ }^{5}$ School of Resources and Earth Science, China University of Mining and Technology, Xuzhou, Jiangsu 221116, China \\ Correspondence should be addressed to Wei Shen; 826618111@qq.com and Guang-Jian Liu; liuguangjian5@usx.edu.cn
}

Received 30 July 2021; Accepted 28 August 2021; Published 14 September 2021

Academic Editor: Fan Deyuan

Copyright (C) 2021 Wei Shen et al. This is an open access article distributed under the Creative Commons Attribution License, which permits unrestricted use, distribution, and reproduction in any medium, provided the original work is properly cited.

\begin{abstract}
To study fracture evolution and peak stress in burst risk coal samples (BRCSs) under true triaxial loading and unloading conditions, experimental and numerical research was applied to BRCSs under true triaxial stress paths entailing " $x$-direction displacement fixed, $y$-direction loading, $z$-direction unloading." Both the experimental and the numerical results demonstrated that the peak stress borne by the BRCSs was not only affected by the initial stress but also had a negative exponential relationship with the ratio of the unloading rate and the loading rate (RURLR); therefore, peak stress equations of BRCSs under true triaxial loading and unloading conditions were established. The triaxial stress-time curves obtained by experiments and simulations exhibited an "elasticity-yield-destruction" phase, and the characteristics of the yield phase were determined by the RURLR. A typical BRCS was selected for velocity tomographic imaging to analyze the fracture evolution characteristics under true triaxial loading and unloading. The results showed that when the BRCS was subjected to a triaxial state of stress, the high- and low-velocity regions existed alternately due to the presence of the crack; during the elastic phase, the crack closed during loading in the previous phase was reopened upon unloading, so that the velocity of the sample decreased and a wide range of low-velocity regions could be formed; when entering the yield phase, the original crack continued to expand into a hole-through crack, leading to wider extreme values and ranges of these low- and high-velocity regions; at the breaking phase, multiple microcracks were generated around the hole-through cracks, decreasing the overall velocity, and showing point distributions characteristics of high- and low-velocity regions. Overall, many low-velocity regions with similar normal directions to the unloading direction were formed; these correlated well with macrofractures (postfailure).
\end{abstract}

\section{Introduction}

As the mining depth increases, rock burst becomes a serious mine disaster, which restricts the safety production of the coal mine [1-3]. The occurrence of rock burst is induced by many factors. According to statistics, the rock burst mainly occurs in the roadway (91\%) during mining and driving.
During the mining period, the production personnel are mainly located under the hydraulic of working face, and few personnel are in the roadway. So, personnel are less likely injured by the rock burst. On the contrary, the personnel are mainly located in the head and the rear of the roadway during the driving, which are just the rock burst prone area. So, it is easier to cause casualties during driving than during 
mining. From the perspective of coal seam properties, the difficulty of rock burst is affected by coal properties. For coal samples with a uniaxial compressive strength greater than $20 \mathrm{MPa}$, the critical stress value of rock burst is only $50 \mathrm{MPa}$, while the uniaxial compressive strength is less than $17 \mathrm{MPa}$, and the critical stress value of rock burst needs to reach $70 \mathrm{MPa}$ [4]. By dividing the coal samples into different hazard levels, the scholar judges the difficulty of rock burst, and rock burst is most likely induced in the strong BRCSs [5-7]. Therefore, the roadway excavation in the strong BRCSs is more likely to cause casualties than the mining and is more likely to cause rock burst than the weak BRCSs; therefore, it has more research value.

With the driving disturbance [8], the initial rock stress state is broken, and the free surface radial stress of the surrounding rock instantaneously reduces to zero, which shows obvious radial unloading; the roof is continuously falling in the vertical direction of the surrounding rock, which shows apparent loading on the coal body; the trending direction of the surrounding rock is constrained by the adjacent coal body. The surrounding rock exhibits the triaxial stress path characteristic of "load-unload-displacement fixation." According to numerous previous studies in the literature [9-11], the stress-strain paths have an important effect on the stress variation and fracture form of coal samples.

In order to better understand the stress characteristics and fracture mechanism of rocks under true triaxial loading and unloading conditions, many experimental and numerical investigations on rocks have been carried out. Based on the stress path of the underground engineering excavation, Du et al. [12] carried out true triaxial unloading compressive test and found the failure modes of the granite and red sandstone specimens changed from shear to slabbing with the increase of $\sigma^{2}$. Su et al. [13] carried out the experiments with a loading path that maintained one face free and applied loading along three axial directions on the other five faces and found that the tunnel axis stress has a significant influence on the strain burst characteristics. In the true triaxial loading-unloading test, Li et al. [14] found the total strain energy, elastic strain energy, and circumferential strain energy all increase as the initial confining pressure increases, whereas the dissipative strain energy does not. Chen et al. [15] carried out an experiment with one face kept free and the other five faces loaded and found that rock burst occurrence depends on several conditions, including specifically the tangential loading rate exceeding a certain threshold, the presence of considerable amounts of stored strain energy, the dissipation of energy through rock splitting on the free face, and the shear failure in the potential rock burst pit. Zhao et al. [16] found that the rock samples are prone to strain burst failure under a high unloading rate and the associated acoustic emission energy release in the strain burst process is dependent on the unloading rate. Yin et al. [17] studied the influence of true triaxial loading and unloading rate on energy characteristics of sandstone and found that the dissipated energy ratio increased first, then decreased, and finally increased with the increase of maximum principal strain. The dissipated energy ratio decreased with the increase of unloading rate at peak stress and increased with the increase of loading rate. Wang et al. [18] studied the effects of loading and unloading conditions on mechanical behaviors of sandstone and mudstone and found that the mechanical behaviors obtained from the unloading triaxial tests, such as the specimens' failure surface, strain-stress curve, triaxial compressive strength, and triaxial shear strength, are different from ones obtained from the conventional triaxial tests. Feng et al. [19] found that the peak strength is nonsymmetrical with the increasing $\sigma^{2}$ and is closely related to the lode angle, and the strength variation exhibited a close relationship to the failure mechanism. Liu et al. [20] found that preexisting flow planes play significant roles in the strength levels, failure modes, and permeability levels under true triaxial stress paths. Zhu et al. [21] found that bursting failure occurs when the axial stress is more than three times the uniaxial compressive strength of the coal sample under a constant confining pressure. Zhao et al. [22] simulated the stress change of a rock mass in front of the working face during underground excavation and found that the total absorption energy, elastic strain energy, and dissipation energy increased with the loading rate increased. For a given loading rate, more cracks were formed by consuming less energy under a high unloading rate. Yang [23] found that higher initial unloading confining pressure is associated with earlier and more severe failure after peak stress. Faster unloading rates are also associated with earlier sample destruction after peak stress because the coal rapidly changes from a triaxial stress state to a uniaxial stress state with a higher unloading rate, crack propagation is insufficient, and more elastic energy is released. Zhang et al. [24] found that the test results show that the triaxial unloading strength of coal samples under different test conditions is lower than conventional triaxial tests, but the brittleness characteristics are more obvious. Si and Gong [25] found that under the same confining pressures, the variations in peak strength of granite specimens are in the following order: triaxial compression test biaxial compression test $>$ triaxial unloading compression test under low unloading rate $>$ triaxial unloading compression test under high unloading rate, which indicates that unloading induces an obvious strength-weakening effect on finegrained granite.

In the experimental process, acoustic emission [26-28], photographic monitoring techniques [29, 30], tomography techniques [31, 32], and other methods $[33,34]$ have been used to monitor and analyze spatial distributions of microfractures in rocks. Tomography techniques have been used in the laboratory because of their many advantages including techniques penetration, relatively minor errors, and visualization [31, 32]. Cao et al. [31] used passive velocity tomography to study characteristics of mudstone during uniaxial deformation and found that high-velocity regions can be used for the prediction of large energy AE events in rocks. Goodfellow et al. [32] conducted a true triaxial test using attenuation tomography and found that attenuation properties could reflect the damage status in Fontainebleau sandstone at different loading phases. 
The previous studies enrich the understanding of the mechanical characteristics and fracture characteristics under the condition of true triaxial loading and unloading. However, the effect of the RURLR is not considered in calculating the peak stress, and the study of the BRCS simulation under triaxial loading and unloading is not found. It is not found that the characteristics of the fracture evolution during the true triaxial loading and unloading process were analyzed by the velocity tomography. These are the research key contents of this paper. In this paper, the experimental and numerical methods are used to study the mechanical and fracture evolution characteristics of BRCSs under the triaxial loading and unloading, so as to provide a reference for the risk prediction of roadway driving in burst risk coal seams.

\section{Experiments and Simulations of BRCSs}

According to the introduction, our predecessors have used experimental and numerical methods to study the stress equation and fracture characteristics under the condition of true triaxial loading and unloading. The two methods have their own advantages and disadvantages: the coal samples naturally contain multiple fracture units, which results in a certain dispersion of their mechanical characteristics, but the experimental method can better reflect the evolution of the natural coal samples. The results obtained by the numerical simulation method can reflect the mechanical characteristics of the sample with certain physicomechanical parameters, but its description of the fracture evolution of the natural coal samples is poor, especially when using finite element analysis. Therefore, in the present work, experiments and simulations are both used to study the mechanical and fracture evolution characteristics under true triaxial loading and unloading.

2.1. Experimental Methods and Procedures. The stress paths applied in the experiments entail " $x$-direction displacement constant, $y$-direction loading, $z$-direction unloading." The specimens are cubes with a side length of $70.7 \mathrm{~mm}$.

Two schemes were adopted. (1) The effect of RURLR: the samples are loaded to initial stress of $25 \mathrm{MPa}$, and then the $Y$-axis is loaded at a certain rate; the ratio of the $Z$-direction unloading rate to the $Y$-direction loading rate is shown in Table 1; the $X$-direction displacement is kept constant until the sample is destroyed. (2) The effect of initial stress: the samples are loaded to different initial stresses (see Table 1); then the ratio of the unloading rate in the $Z$-direction to the loading rate in the $Y$-direction is set to 1.5 for true triaxial loading and unloading tests. The displacement in the $X$ direction is kept constant until the sample is destroyed.

During each experiment, the acoustic emission events were monitored by using a PCI-2 acoustic emission acquisition system equipped with eight Micro-80S miniature AE probes. The acoustic emission probes are embedded in an iron block, and the surfaces of the probes are coated with Vaseline ${ }^{\circledR}$ to couple them to the coal samples (as shown in Figure 1); a layer of rubber is placed between the iron block and the coal to prevent the wave propagating through the iron block to the probes, thereby improving the accuracy of waveform signal monitoring.

\subsection{FLAC ${ }^{3 D}$ Simulation Analysis}

2.2.1. Model for True Triaxial Loading-Unloading Modeling. FLAC $^{3 \mathrm{D}}$ was used for the numerical calculation of mechanical properties under true triaxial loading and unloading. The train-softening criterion was used to simulate the coal samples. The model size was $70.7 \mathrm{~m} \times 70.7 \mathrm{~m} \times 70.7 \mathrm{~m}$, and the stress paths applied in the simulations were the same as those of experiments. Moreover, the simulation schemes being adopted were also the same as the experimental schemes, analyzing the influence of initial stress and unloading ratio on true triaxial loading and unloading test, which are listed in Table 1.

2.2.2. Simulation Parameter Calibration. The test samples are columnar with a height of $100 \mathrm{~mm}$ and a diameter of $50 \mathrm{~mm}$. The strain-softening model is selected for the uniaxial compression simulation. The purpose of the simulation is to determine the loading rate used in the static tests and the mesoscopic parameters of the BRCSs for use in numerical simulation.

(1) Selection of Most Appropriate Load Rate. According to He et al.'s research [35], the static, monotonic cross-head displacement rate applied to coal samples should be less than $0.001 \mathrm{~mm} / \mathrm{s}$; otherwise, the coal samples exhibit dynamic mechanical characteristics. Therefore, determining the most appropriate static loading rate is an important part of the simulation. The stress-strain curves of the uniaxial compression process at different loading rates are shown in Figure 2. At a loading rate of $0.01 \mathrm{~mm} / \mathrm{step}$, the stress on the sample immediately reaches $10 \mathrm{MPa}$, the stress changes significantly in each time step, and the stress-strain curve fluctuates in an irregular manner; at this loading rate, the stress is highly concentrated, forming plastic failure zones at both ends (Figure 3(a)), and then the stress and plastic zone expand to the middle of the sample, which shows the dynamic failure characteristics. When the loading rate is less than $0.001 \mathrm{~mm} / \mathrm{step}$, the stress curve exhibits a regular "elastic-plastic-destructive" characteristic. The stress concentration and plastic failure zones first form in the middle of the sample (Figures 3(b) and 3(c)) and then extend toward each end, typifying static failure.

Figure 2(b) shows the stress-strain curves of the samples under uniaxial compression at different loading rates: when the loading rate is less than $0.001 \mathrm{~mm} / \mathrm{step}$, the uniaxial compressive strength is almost constant as the loading rate increases. Otherwise, the uniaxial compressive strength increases rapidly, showing a characteristic that the strength is affected by strain rate.

In summary, the load rate applied to a simulated sample should be kept within $0.001 \mathrm{~mm} / \mathrm{step}$, thus avoiding the influences thereof the on strength and fracturing of samples. 
TABLE 1: The effect test of RURLR and initial stress.

\begin{tabular}{|c|c|c|c|c|}
\hline Test content & Initial stress $(\mathrm{MPa})$ & Loading rate $(Y$-axis $)(\mathrm{mm} / \mathrm{min})$ & Unloading rate $(Z$-axis $)(\mathrm{mm} / \mathrm{min})$ & RURLR \\
\hline \multirow{5}{*}{ RURLR } & \multirow{5}{*}{25} & \multirow{5}{*}{1} & 0.5 & 0.5 \\
\hline & & & 1 & 1 \\
\hline & & & 1.5 & 1.5 \\
\hline & & & 2 & 2 \\
\hline & & & 2.5 & 2.5 \\
\hline \multirow{5}{*}{ Initial stress } & 6.25 & \multirow{5}{*}{1} & \multirow{5}{*}{1.5} & \multirow{5}{*}{1.5} \\
\hline & 12.5 & & & \\
\hline & 18.75 & & & \\
\hline & 25 & & & \\
\hline & 31.25 & & & \\
\hline
\end{tabular}

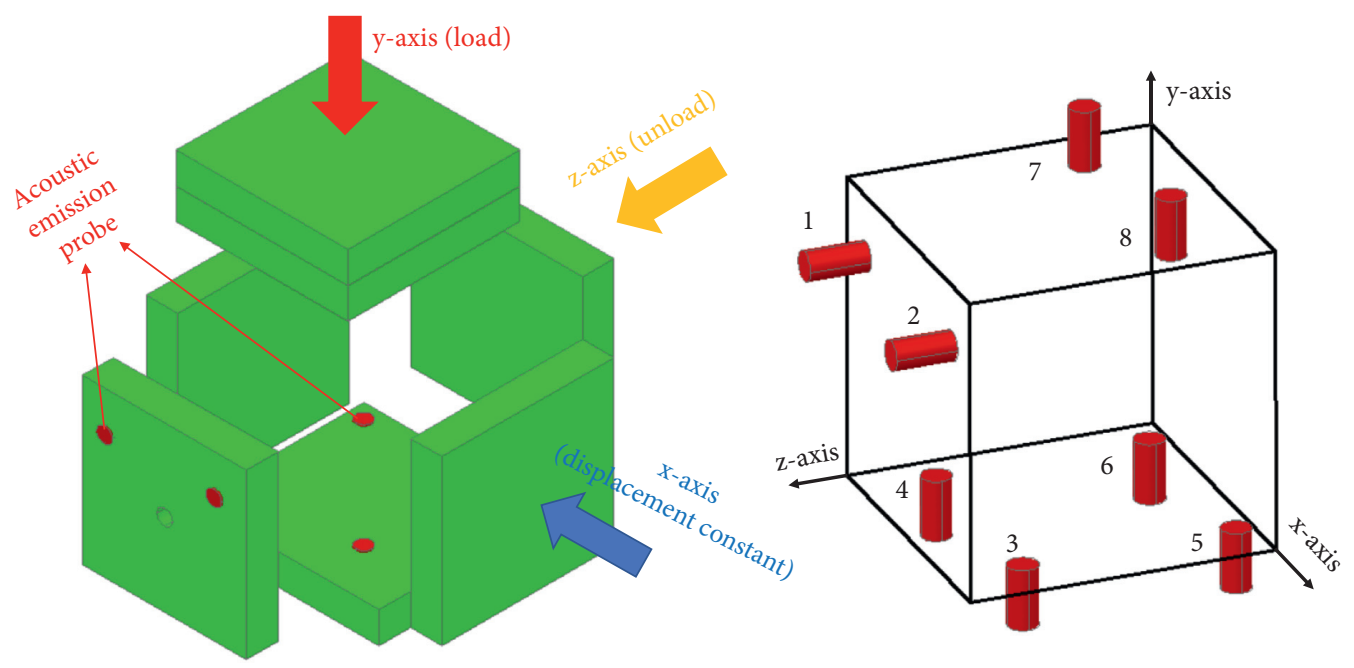

Figure 1: Layout of the triaxial clamps and acoustic emission probes.

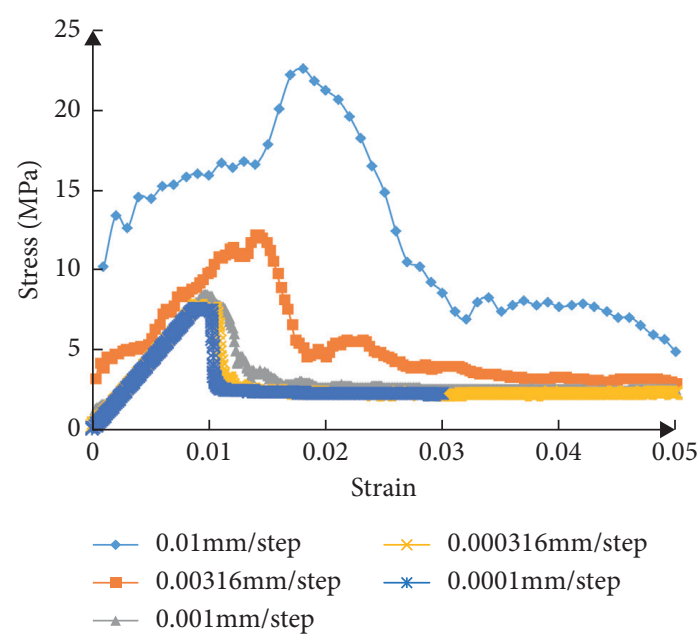

(a)

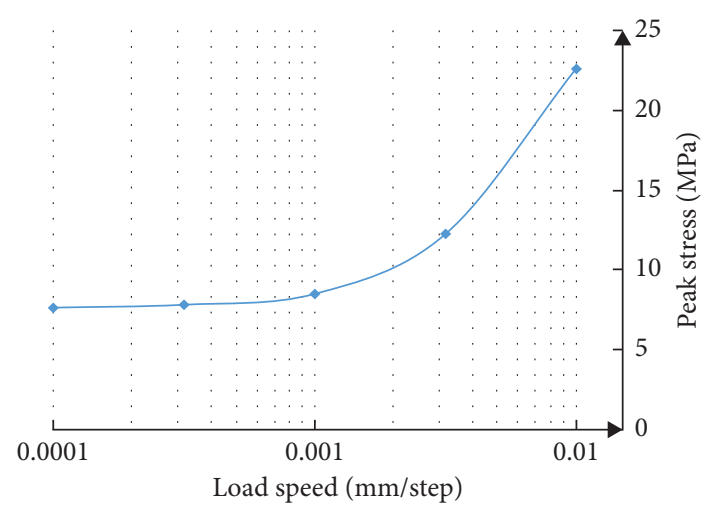

(b)

Figure 2: (a) Stress-strain curves and (b) uniaxial compressive strengths at different loading rates.

(2) Mesoparametric Calibration. The macromechanical parameters are determined by the mesomechanical parameters, such as cohesive force and internal friction angle. The mesomechanical parameters are calibrated by comparison with the experimental results of BRCSs. The relevant mesoparameters used in the FLAC model are summarized in Table 2. The uniaxial compressive stress-strain curves obtained by the simulations and experiments under uniaxial 


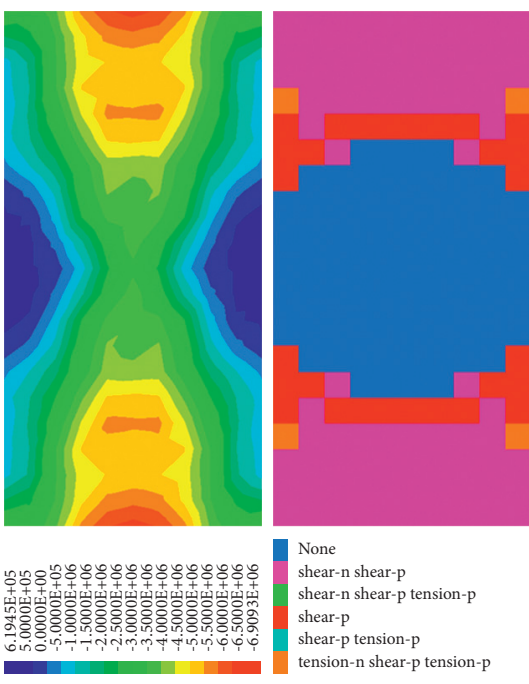

(a)

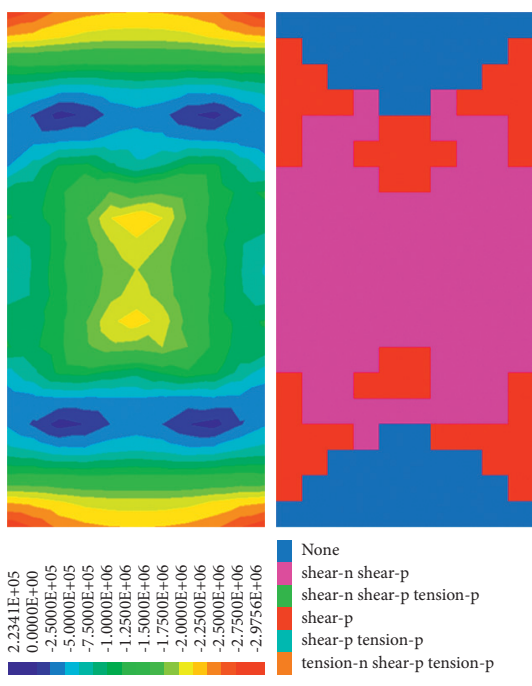

(b)

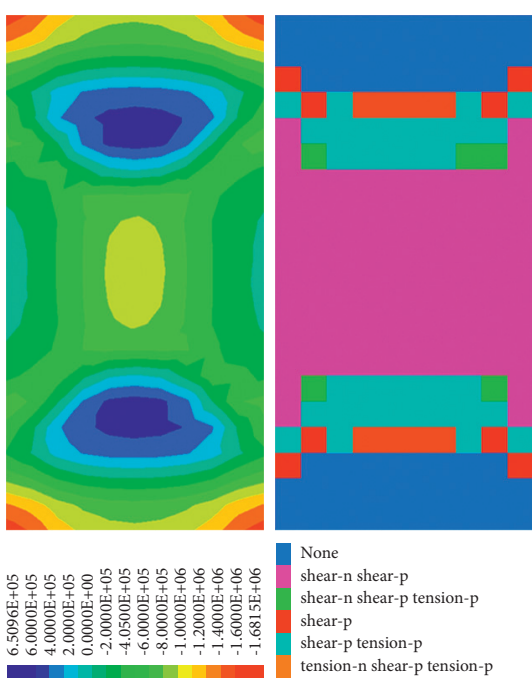

(c)

FIGURE 3: Stress cloud maps and plastic regions at different loading rates. (a) $0.01 \mathrm{~mm} / \mathrm{step}$. (b) $0.001 \mathrm{~mm} / \mathrm{step}$. (c) $0.0001 \mathrm{~mm} / \mathrm{step}$.

TABLE 2: Mesoscale parameters used in the FLAC model.

\begin{tabular}{lcccccc}
\hline Lithology & $\begin{array}{c}\text { Density }(\mathrm{kg} / \\
\left.\mathrm{m}^{3}\right)\end{array}$ & $\begin{array}{c}\text { Bulk modulus } \\
(\mathrm{GPa})\end{array}$ & $\begin{array}{c}\text { Shear modulus } \\
(\mathrm{GPa})\end{array}$ & $\begin{array}{c}\text { Cohesion } \\
(\mathrm{MPa})\end{array}$ & $\begin{array}{c}\text { Internal friction angle } \\
\left({ }^{\circ}\right)\end{array}$ & $\begin{array}{c}\text { Tensile strength } \\
(\mathrm{MPa})\end{array}$ \\
\hline BRCS & 1400 & 0.38 & 0.18 & 2.5 & 30 & 1 \\
\hline
\end{tabular}

compression are shown in Figure 4. The blue stress-strain curve is obtained by simulations, and the yellow curve is acquired by experiments.

As shown in Figure 4(a), the stress-strain curve obtained experimentally has a compacting phase due to the presence of initial cracks in the coal samples. If the compaction phase of the experimental sample is not considered, the experimental and numerical stress-strain curves are similar: the same elastic modulus $(0.85 \mathrm{GPa})$, peak intensity (about $8 \mathrm{MPa}$ ), and stress drop are observed in the postpeak stressstrain curve. Figure 4(b) shows that the fractures (in numerical simulations) are concentrated in the middle of the specimens; acoustic emission events logged during testing arise mainly from the middle of the BRCSs, indicating a form of fracture similar to that modeled numerically. Therefore, the stress-strain curve and failure characteristics of the numerical sample with mechanical properties listed in $\mathrm{Ta}$ ble 1 agree well with the experimental data.

\section{Analysis of Results}

3.1. Stress Curve Characteristics. The typical triaxial stresstime curves of the sample under true triaxial loading and unloading for simulations and experiments are shown in Figure 5. The triaxial stress-time curves are divided into three distinct phases.

The first phase (I): due to the unloading action in the $Z$ direction, the stress thereon decreases; however, the stress in the $Y$-direction increases linearly with the applied load and is unaffected by unloading (Figure 5). The coal samples are relatively complete thereat and are able to bear load independently and in an elastic state of stress.

The second phase (II): when the triaxial stress reaches a certain value, the $Y$ - and $Z$-direction stress-time curves show a significant inflection point (the yield point). In this phase, the increasing rate of $Y$-axis stress and the decreasing rate of $Z$-axis stress are significantly smaller than those in the first phase. The variations in the $Y$ - and the $Z$-axis stresses in this phase are influenced by two factors: volumetric expansion due to coal failure and that due to unloading. When the volumetric expansion at failure is greater than that caused by unloading, the coal body compresses, increasing the stresses in the $Y$ - and $Z$-directions. On the contrary, the coal body is subjected to tension, thus decreasing the stress in the $Y$ - and Z-directions.

The third phase (III): as cracks in the sample develop to a certain extent, both the loading stress and unloading lateral stress begin to change. The lateral stress decreases slowly, while the change upon the unloading side is not as obvious in these tests. The loading and unloading lateral stress curves in the simulation process are different from those measured experimentally: while the loading lateral stress decreases instantaneously, the unloading lateral stress increases instantaneously, and then the loading lateral stress and unloading lateral stress change slowly and in tandem. The reason for this difference in stress is that the coal samples used in the experiment contain many cracks, whose propagation under stress ultimately leads to failure of the sample, while simulated samples are homogeneous, resulting in instantaneous large-scale destruction when the ultimate 

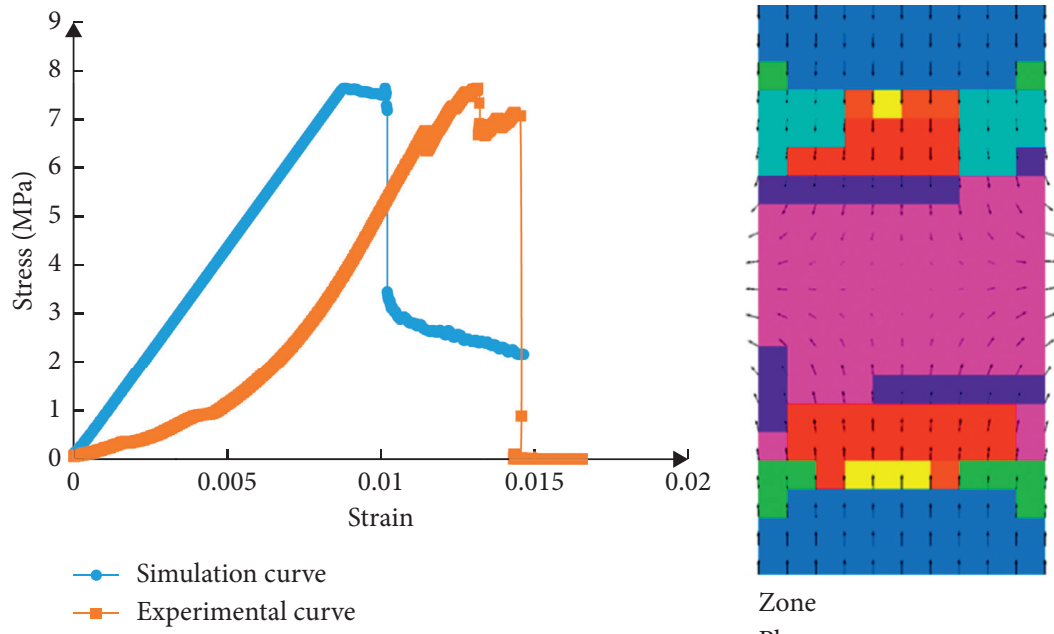

Zone

Plane: on

Colorby: State -Average

- None

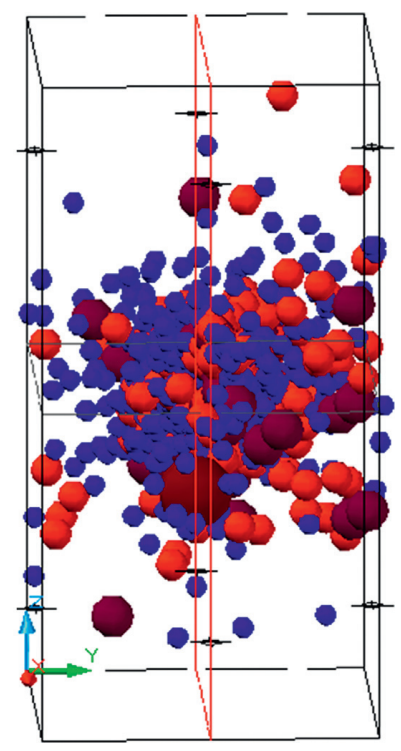

chear-n shear-p

- shear-n shear-p tension-p

shear-p

shear-p tension-p

tension-n shear-p tension-p

tension-n tension-p

tension-p

(a)

(b)

FIGURE 4: Comparison of (a) stress-strain curves and (b) failure mode obtained by the experimental and numerical sample.

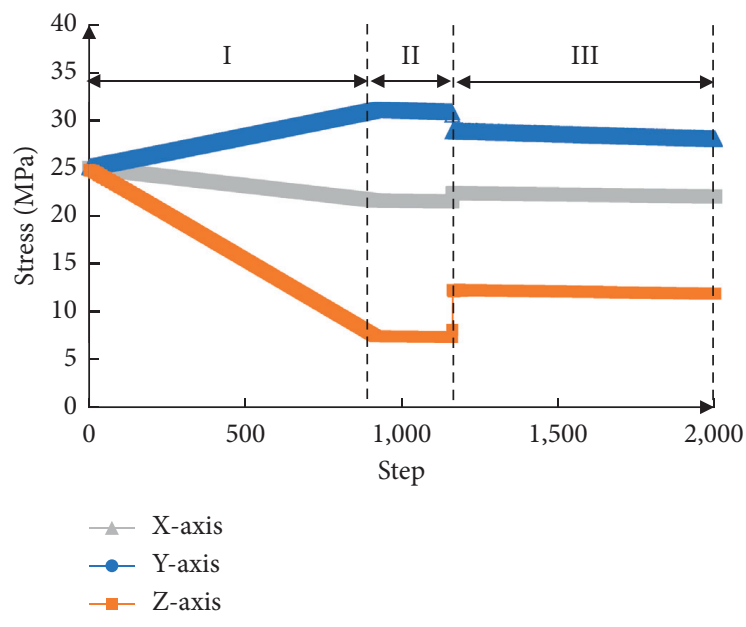

(a)

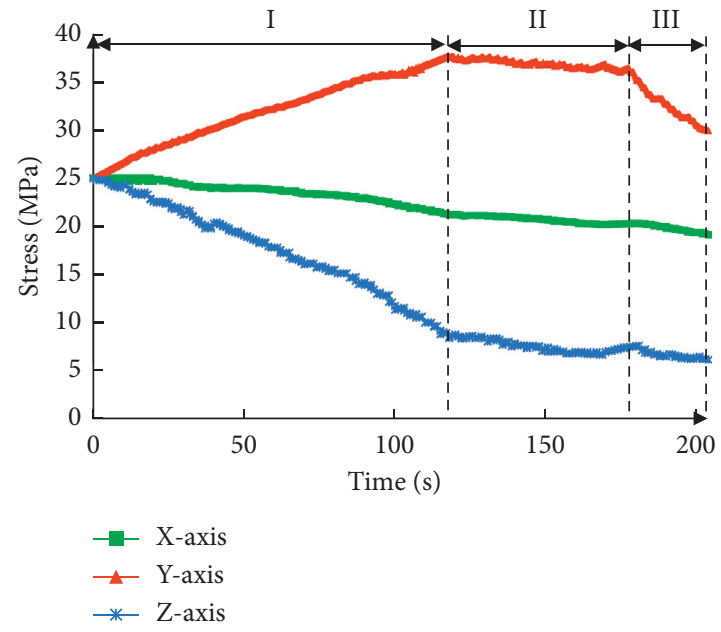

(b)

FIGURE 5: The triaxial stress-time curve for simulations and experiments under true triaxial loading and unloading. (a) Numerical curve. (b) Experimental curve.

stress is reached. The kinetic energy is mobilized in the direction of the minimum principal stress, which results in the instantaneous stress increase in this direction. During the whole true triaxial loading and unloading test, the fixed side ( $X$-axis) stress variation is small, showing only a slight increase or decrease.

\subsection{Peak Stress}

3.2.1. Factors Affecting the Peak Stress. The peak stress refers to the three-dimensional stress when the applied stress reaches its ultimate limiting value during the test. At this time, the stress on the loading axis is called the loading 
lateral peak stress, and the stress on the unloading axis is called the unloading lateral peak stress.

(1) The RURLR. A comparison of the experimental and numerical peak stress at the loading and unloading side with different RURLRs is shown in Figure 6. It can be seen from the results that the experimental values match the numerical values. When the RURLR is 0.5 , the loading lateral peak stress of the sample is $80 \mathrm{MPa}$, and the unloading lateral peak stress is $24 \mathrm{MPa}$. When the RURLR increases to 2.5 , the peak stress on the loading side decreases to $25 \mathrm{MPa}$ and the peak stress of the unloading side decreases to $5 \mathrm{MPa}$. From numerical and experimental results, the peak points of the loading and unloading lateral stress decrease exponentially with the increase of the RURLR.

(2) Initial Stress. A comparison of the experimental and numerical peak stresses at the loading and unloading lateral side under different initial stresses is shown in Figure 7. It can be seen from the results that the experimental values match the simulated values. When the initial stress is $6.25 \mathrm{MPa}$, the loading lateral peak stress of the sample is about $11 \mathrm{MPa}$, and the unloading lateral peak stress is $0 \mathrm{MPa}$. When the initial stress increases to 31.25 MPa, the loading lateral peak stress reaches $40 \mathrm{MPa}$ and the unloading lateral peak stress reaches $10 \mathrm{MPa}$. From numerical and experimental results, we see that the loading and unloading lateral peak stress increases linearly with increasing initial stress.

\subsubsection{Equation of Peak Stress}

(1) Equation Construction. According to the true triaxial stress path experiment, the loading and unloading lateral peak stress increases exponentially with the increase of the RURLRs. The relationship between the peak stress and the RURLR is given by

$$
\sigma_{\max }=a * h^{\prime-b}+c,
$$

where $\sigma_{\max }$ is the peak stress on the loading side and the unloading side; $a, b$, and $c$ are coefficients to be determined; and $h^{\prime}$ is the RURLR.

The loading and unloading lateral peak stress increases linearly with the initial stress, so

$$
\sigma_{\max }=A * \sigma_{c}+B,
$$

where $\sigma_{\max }$ is the loading and unloading lateral peak stress, $A$ and $B$ are coefficients to be determined, and $\sigma_{c}$ is the initial confining pressure.

The boundary conditions on the loaded side are as follows: when the initial stress is zero, there is no unloading effect in the $Z$-direction, which is equivalent to a uniaxial compression test; at this point, $\sigma_{c}=0$ is substituted into equation (2) and $B=R_{c}$ is obtained. When the rate of unloading in the $Z$-direction is infinite $\left(h^{\prime}=+\infty\right)$, the $Z$-axis stress drops to zero instantaneously (i.e., representative of a uniaxial compression test); at this point, $h^{\prime}=+\infty$ is substituted into equation (1) and $c=R_{c}$ is obtained. When the rate of unloading along the $Z$-axis is zero $\left(h^{\prime}=0\right)$, there is only a loading effect in the $Y$-direction, and the $X$ - and $Z$ axis displacements are fixed; at this point, $\sigma_{\max }=+\infty$.

Based on the boundary conditions of the loading side, equations (1) and (2) can be combined to give the loading lateral peak stress as shown in

$$
\sigma_{y \max }=a_{1} \cdot \sigma_{c} \cdot h^{\prime-b_{1}}+R_{c},
$$

where $\sigma_{\mathrm{ymax}}$ is the loading lateral peak stress, $a_{1}$ and $b_{1}$ are coefficients to be determined, and $R_{c}$ is the uniaxial compressive strength.

(2) Modification of Equations. When the initial stress is small, the $Z$-axis stress is unloaded to zero, and that along the $Y$-axis just reached the uniaxial compressive strength, giving

$$
\left\{\begin{array}{l}
E \cdot \varepsilon_{y}+\sigma_{c}^{\prime}=R_{c}, \\
E \cdot \varepsilon_{z}=\sigma_{c}^{\prime},
\end{array}\right.
$$

where $E$ is the stress-strain slope, $\varepsilon_{y}$ is the strain in the $Y$ direction, $\varepsilon_{z}$ is the strain in the $Z$-direction, and $\sigma_{c}^{\prime}$ is the initial stress.

From equation (4), initial stress can be obtained; thus,

$$
\sigma_{c}^{\prime}=R_{c} \cdot \frac{h^{\prime}}{h^{\prime}+1}
$$

where $h=\varepsilon_{y} / \varepsilon_{z}$ is the RURLR.

The initial stress in equation (3) is subtracted from $\sigma_{c}^{\prime}$ in equation (5), and the modified expression of peak stress at the loading side can be obtained as follows:

$$
\sigma_{y \max }=a_{1} \cdot\left(\sigma_{c}-R_{c} \cdot \frac{h^{\prime}}{h^{\prime}+1}\right) \cdot h^{h^{-b_{1}}}+R_{c} .
$$

Similarly, according to the unloading lateral boundary limit condition, the unloading lateral stress peak stress is given by

$$
\sigma_{z \max }=a_{2} \cdot\left(\sigma_{c}-R_{c} \cdot \frac{h^{\prime}}{h^{\prime}+1}\right) \cdot h^{\prime-b_{2}},
$$

where $a_{1}, a_{2}, b_{1}$, and $b_{2}$ are coefficients to be determined.

(3) Calculation of Undetermined Coefficients. The values of the coefficients, $a_{1}, a_{2}, b_{1}$, and $b_{2}$, are obtained by introducing the peak stress points of the loading and unloading side under different RURLRs and initial stresses into equations (6) and (7), respectively. The stress equation at the peak point of the loading side under the true triaxial stress path is given by

$$
\sigma_{l \max }=1.72 \cdot\left(\sigma_{c}-8 \cdot \frac{h^{\prime}}{h^{\prime}+1}\right) \cdot h^{\prime-0.9}+8 .
$$

The stress at the peak point of the unloading side under a true triaxial stress path is given by 


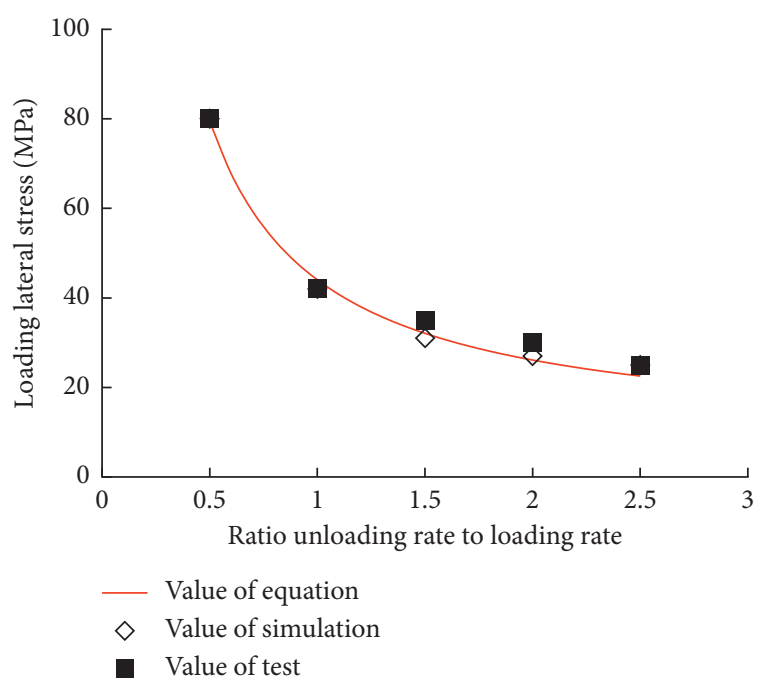

(a)

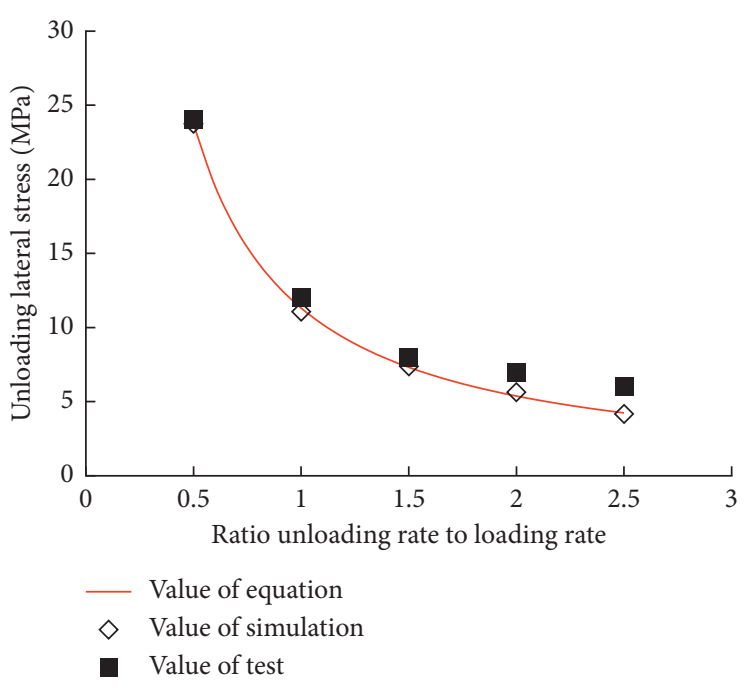

(b)

Figure 6: Peak stress of samples with different RURLRs. (a) Loading lateral peak stress. (b) Unloading lateral peak stress.

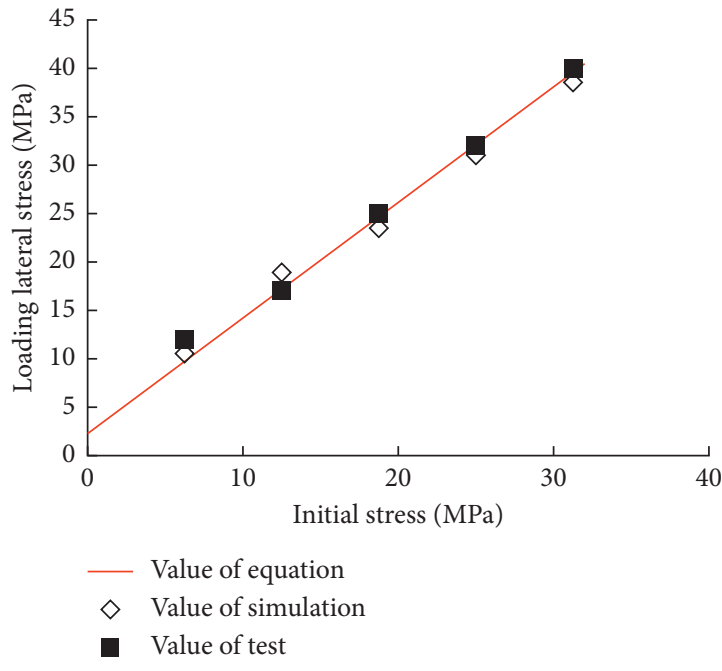

(a)

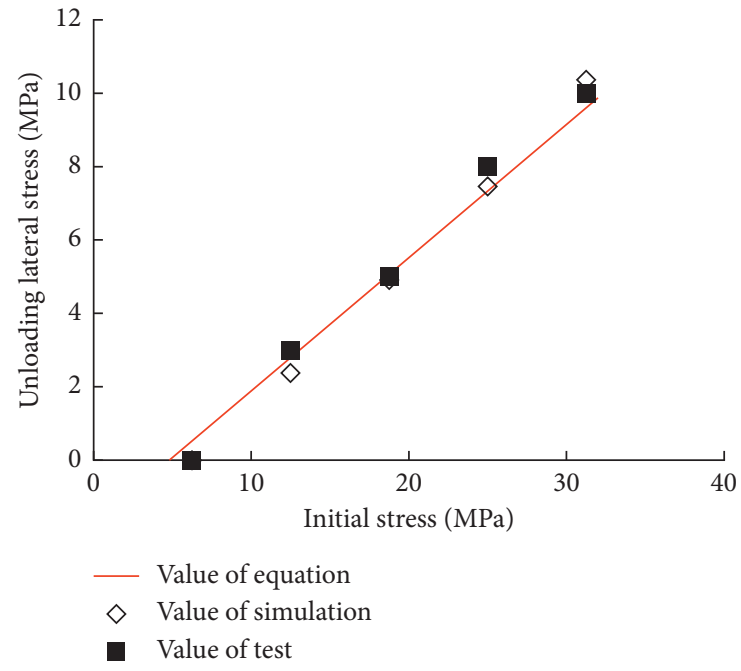

(b)

FIgURE 7: Peak stress of samples with different initial stresses. (a) Loading lateral stress. (b) Unloading lateral stress.

$$
\sigma_{u \max }=0.54 \cdot\left(\sigma_{c}-8 \cdot \frac{h^{\prime}}{h^{\prime}+1}\right) \cdot h^{\prime-0.98}
$$

The peak stress curves of the loading and unloading side obtained from equations (8) and (9) are compared with the peak stress points of the loading and unloading side obtained from experiment and simulation (Figures 8 and 9). The peak stress equation of the loading and unloading side under true triaxial stress is reasonable and effective.

(4) Application of the Equations. Equations (8) and (9) show that the loading axial stress and unloading axial stress of coal mass at peak stress under true triaxial loading and unloading regimes can be obtained from the initial triaxial stresses and the ratio of unloading rate to loading rate. Specifically, for roadway excavation operations, by measuring the initial triaxial stress of the stratum, knowing the rates of axial and radial deformation of the roadway, the triaxial stress when the surrounding rock of the roadway reaches the peak can be estimated.

\subsection{Velocity Tomography Images}

3.3.1. Theory of Velocity Tomography [36, 37]. Tomography requires dividing the body into cubes called voxels in the three-dimensional situation to estimate the body characteristics in all voxels. Suppose that the ray path of the $i$ th acoustic wave is $L_{i}$ and the travel time is $T_{i}$; thus, the time is the integral of the inverse velocity, as described in equations (10) and (11). As an acoustic wave will propagate 


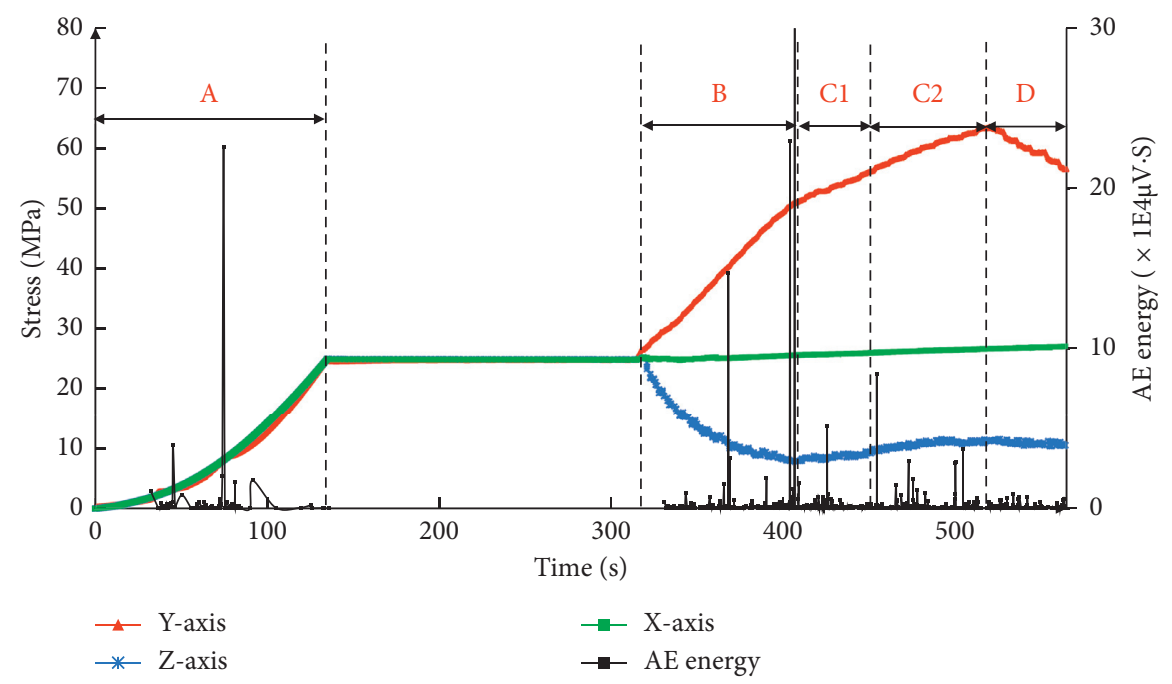

FIGURE 8: Relationship between triaxial stress and acoustic emission energy release.
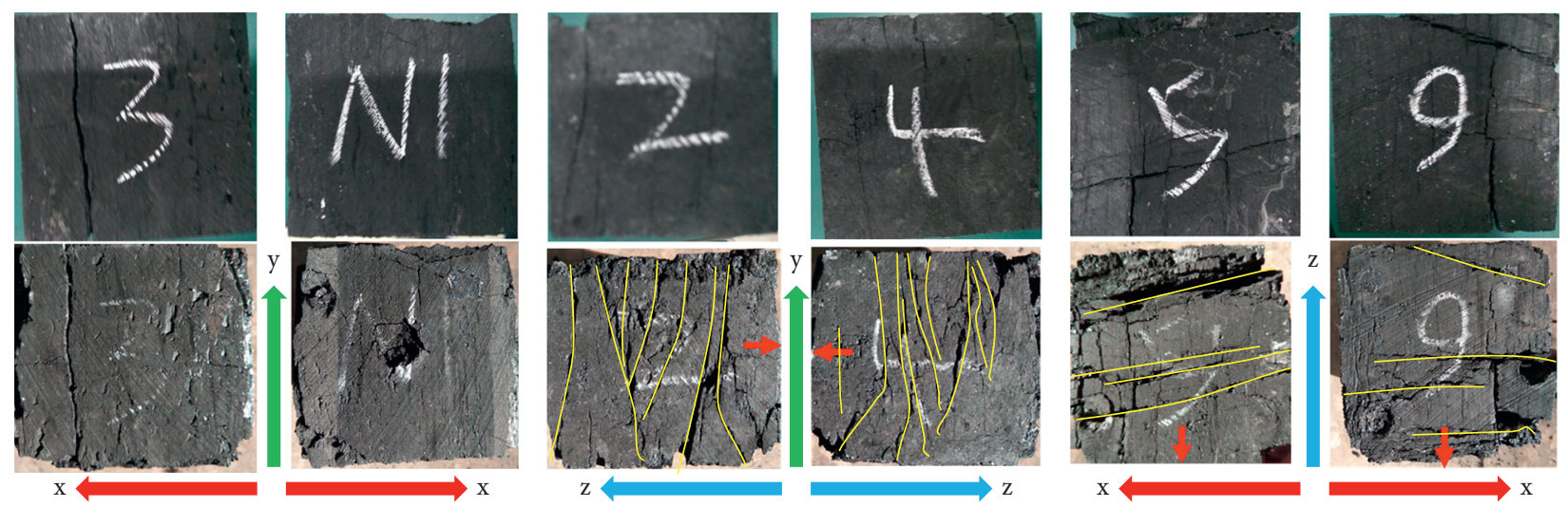

FIGURE 9: Six face-to-face comparisons of coal samples before and after testing (previous row: pretest photographs; following row: posttest photographs).

along a curved path in a heterogeneous medium, ray bending must be taken into consideration for accurate velocity calculation. Thus, the inversion area should be divided into $m$ voxels, and the travel time of the $i$ th ray can be presented as equation (12):

$$
\begin{aligned}
V & =\frac{L}{T} \longrightarrow V T=L \\
T_{i} & =\int_{L_{i}} \frac{\mathrm{d} L}{V(x, y, z)}=\int_{L_{i}} S(x, y, z) \mathrm{d} L, \\
T_{i} & =\sum_{j=1}^{m} d_{i j} S_{j} \quad(i=1, \ldots, n),
\end{aligned}
$$

where $V(x, y, z)$ is the velocity $(\mathrm{m} / \mathrm{s}), L_{i}$ is the ray path of the $i$ th wave $(\mathrm{m}), T_{i}$ represents the travel time $(\mathrm{s})$, and $S(x, y, z)$ is the slowness $(\mathrm{s} / \mathrm{m}) . d_{i j}$ is the distance of the $i$ th ray in the $j$ th voxel, $n$ is the total number of rays, and $m$ is the number of voxels.

Generally, the AE event location and subsequent ray paths are calculated using an initial velocity model.
However, the velocity, distance, and time in an individual voxel are unknown. Thus, arranging the slowness, distance, and time for each voxel into matrices, the velocity can be determined in matrix form as

$$
T=D S \longrightarrow S=D^{-1} T,
$$

where $T$ is the travel time per ray matrix $(1 \times n), D$ is the distance per ray per voxel matrix $(n \times m)$, and $S$ is the slowness per grid cell matrix $(1 \times m)$.

Many studies show that the high-velocity zone corresponds to the high-stress zone, and the low-velocity zone corresponds to the low-stress zone and the fissure zone. Based on this, the stress and fissure distribution law of the sample can be obtained.

3.3.2. Evolution Characteristics of Velocity. The number of samples subjected to true triaxial loading-unloading experiments is large, and the velocity evolution characteristics of samples are roughly the same, so a typical sample was selected for analysis. Figure 8 shows the triaxial stress and acoustic emission energies over the whole experimental 

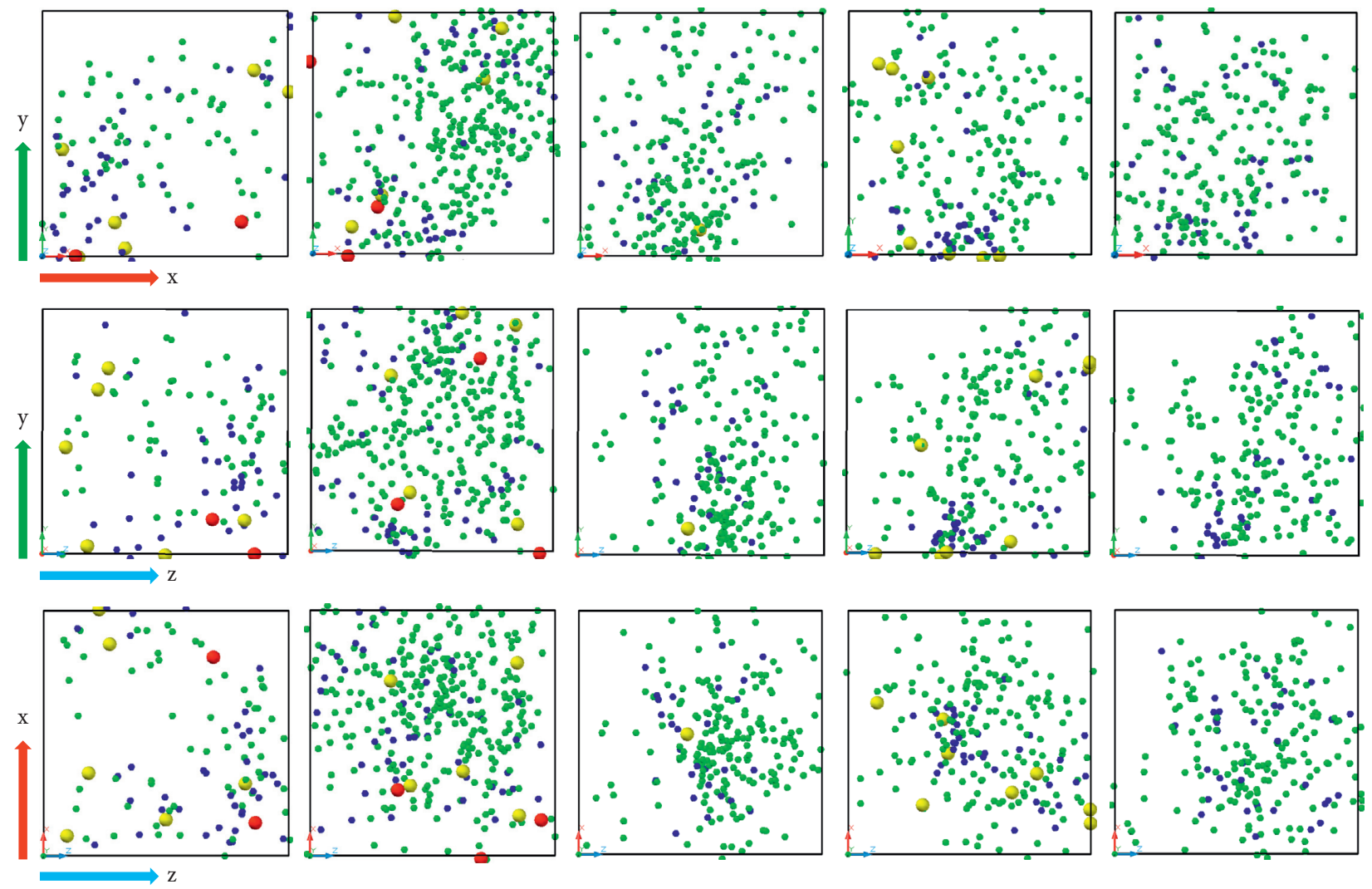

Figure 10: AE event locations in different tomographic phases (left to right: phases A, B, C1, C2, and D).

period. The tomography can be divided into five phases: phase $\mathrm{A}$ is the triaxial stress loading phase, phase $\mathrm{B}$ is the elastic phase of the loading and unloading experiment, phase $\mathrm{C}$ is the yielding phase of the loading and unloading experiment, and phase $\mathrm{D}$ is the failure phase of the loading and unloading experiment. Due to the large number of acoustic emission events in phase $\mathrm{C}$, it is subdivided into two phases, $\mathrm{C} 1$ and $\mathrm{C} 2$. Photographs of specimens before and after testing are shown in Figure 9. The acoustic emission monitoring sites used in each phase are illustrated in Figure 10 , and the velocity tomographic images of each phase are shown in Figure 11.

It can be found from the tomographic phase (phase A, Figure 11(a)) that the continuity of the distribution of lowand high-wave velocity zones is poor on each section of the sample, showing the characteristics of a point-like crossdistribution. The wave velocity range is $0.65 \mathrm{~km} / \mathrm{s}$ to $1.70 \mathrm{~km} / \mathrm{s}$. Figure 9 shows that there are some macrocracks in the sample before the test. The velocity of wave propagation in the fracture region is low, and the bearing capacity is weak. The stress is carried by the intact coal body around the cracked region, which leads to a high velocity in the intact region. Due to the presence of the original cracks, the cross-distribution of high and low velocities is formed in the coal body. As shown in Figure 10, the acoustic emission events are mainly concentrated in the area where there are no obvious cracks $(0 \leq x \leq 35,0 \leq y \leq 35,35 \leq z \leq 70)$ in the sample, which proves that the coal body in intact areas is the main load-bearing area.
From the velocity distribution map of phase B, it can be found that the extent of the high-velocity region decreases, while that with a low velocity enlarges, and the maximum and minimum wave velocities (ranging from $0.55 \mathrm{~km} / \mathrm{s}$ to $1.50 \mathrm{~km} / \mathrm{s}$ ) are lower than those in phase A (Figure 11(b)). This is due to the unloading effect manifested in phase $B$, the density of the sample decreases, and the original cracks closed under compression in phase A reopen, resulting in an enlargement of the low-velocity region and a decrease in the overall wave velocity.

As the test progresses, the sample enters the yield failure state of phase $\mathrm{C}$, wherein new cracks are generated continuously, and the opening of the original cracks also increases, which results in the number of acoustic emission events in phase $C$ being greater than that in phase $\mathrm{B}$, and the range and the extreme values of low wave velocity (the lowest wave velocity was $0.50 \mathrm{~km} / \mathrm{s}$ ) being greater than those in phases $\mathrm{A}$ and $\mathrm{B}$. The formation of new cracks results in the transfer of stress to the surrounding, more intact, coal body, resulting in the increase of stress and extent of the high-stress region. Therefore, the range and extreme values of the high-velocity region (the maximum velocity was $2.00 \mathrm{~km} / \mathrm{s}$ ) in the coal sample are also greater than those in phases A and B. Under the action of new crack formation and increased crack opening, penetrating cracks develop, resulting in vertical low-velocity regions with approximate penetration appearing in coal samples (as evinced by the $x$-direction tomographic slices). 

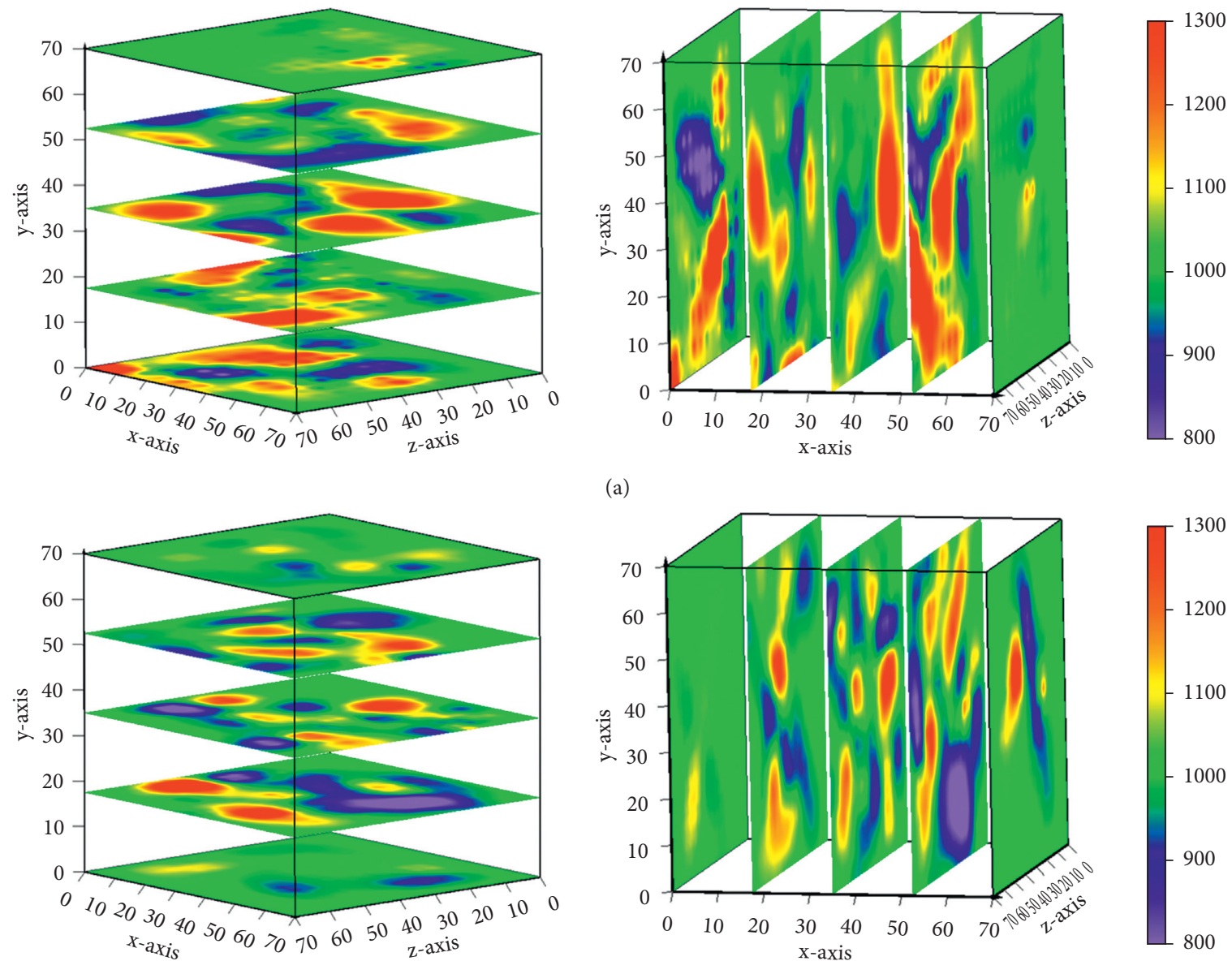

(a)

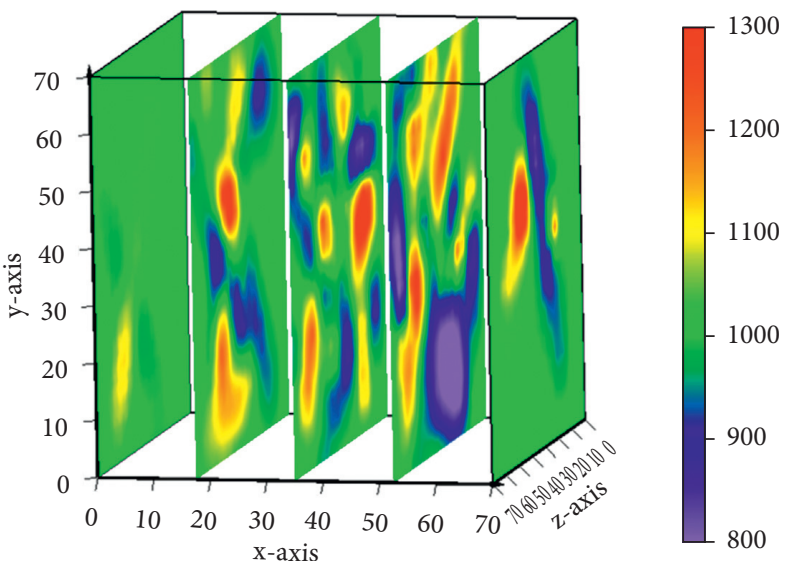

(b)
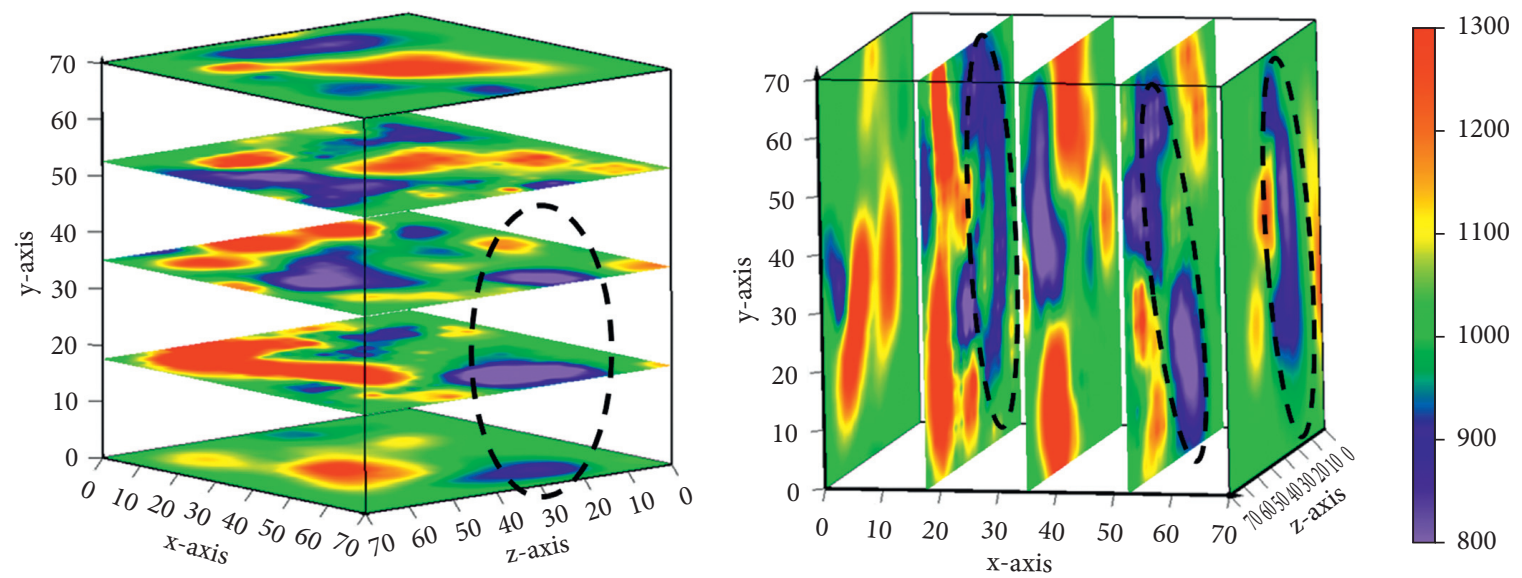

(c)

Figure 11: Continued. 

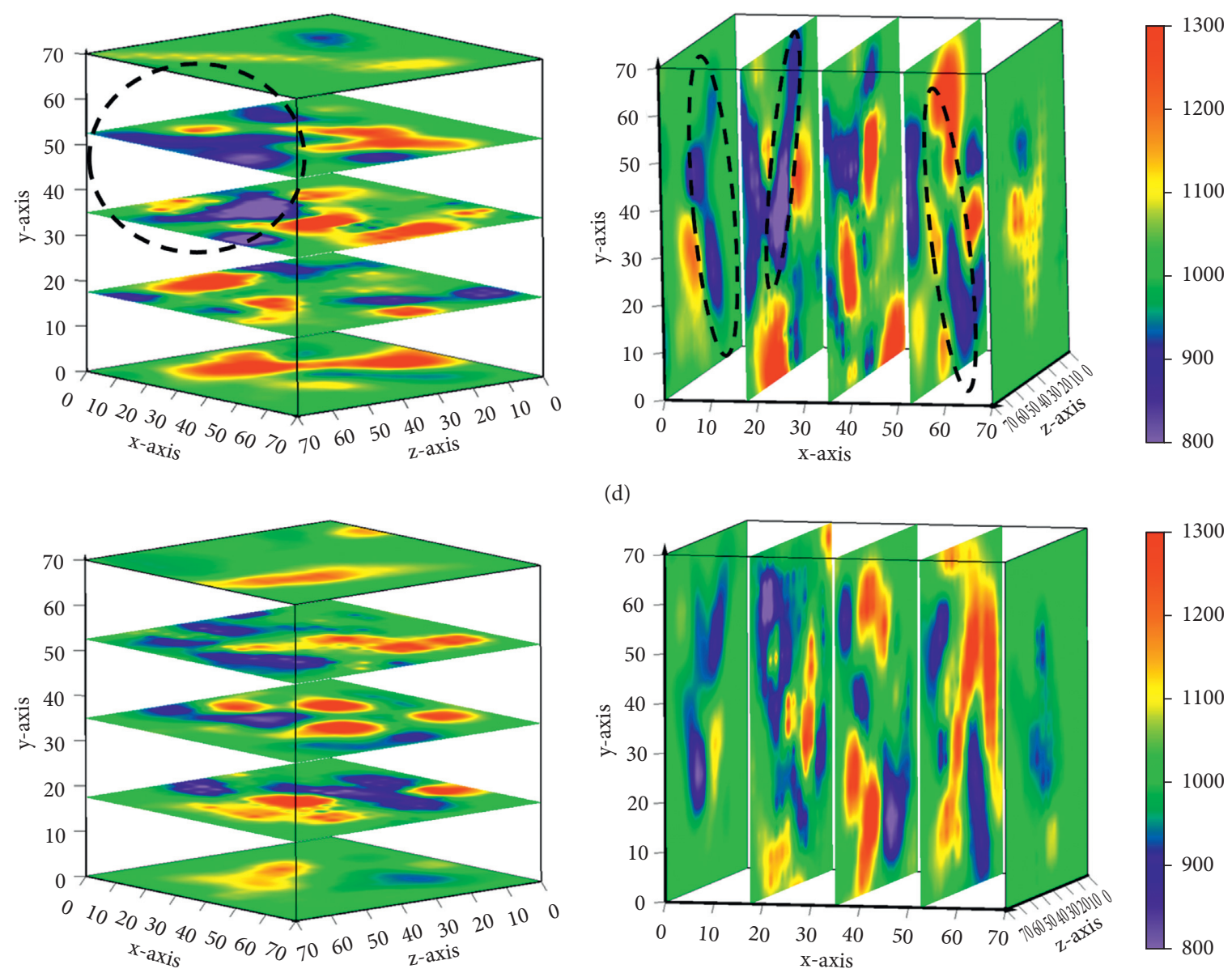

(d)

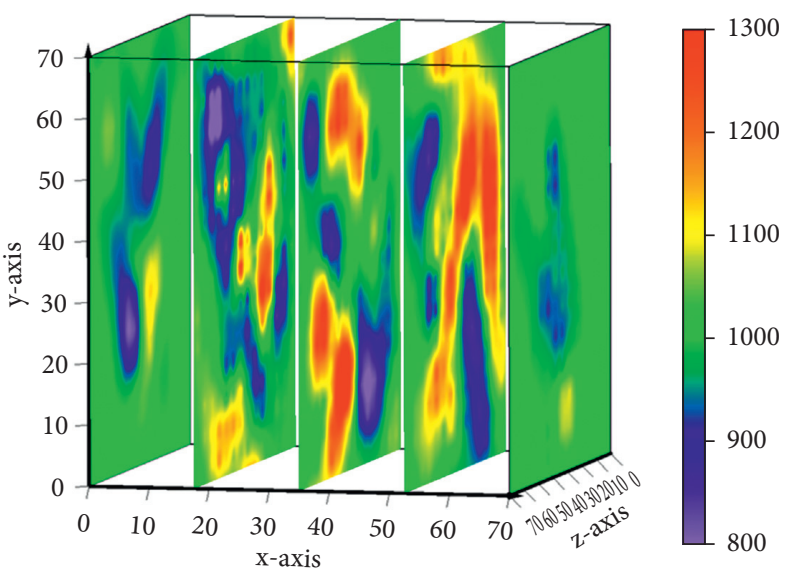

(e)

Figure 11: Tomographic results. (a) Phase A. (b) Phase B. (c) Phase C1. (d) Phase C2. (e) Phase D.

In phase $\mathrm{C} 1$, the low-wave-velocity region is mainly distributed within $0 \leq Z \leq 35 \mathrm{~m}$ near the unloading face, and the high-wave-velocity region is mainly distributed within $35 \leq Z \leq 70 \mathrm{~m}$, suggesting that cracks are formed near the unloading face, and the main load-bearing stress zone is far from the unloading surface. In phase $\mathrm{C} 2$, the region with $35 \leq Z \leq 70 \mathrm{~m}$ changes from being a high-velocity region to a low-velocity region, and it also accounts for most acoustic emission events (Figure 10), reflecting the fact that cracks have propagated from a position near the unloading surface to throughout the specimen.

It can be seen from the range of velocity distributions in phase $\mathrm{D}$ that the penetrating low-velocity zones gradually disappear, and the range and extreme value of the high- and low-wave-velocity zones (ranging from $0.63 \mathrm{~km} / \mathrm{s}$ to $1.50 \mathrm{~km} / \mathrm{s}$ ) also decreased. This is due to the expansion of the coal body, which decreases the opening displacement of large through cracks and forms many microcracks, resulting in poorer continuity of high- and low-velocity regions than in phase $\mathrm{C}$.

Throughout the experimental process, many low-velocity zones with their normal direction approximately parallel to the unloading direction are formed; this is in good agreement with the many cracks, approximately parallel to the unloading surface, formed in the experiment (Figure 9).

\section{Conclusions}

(1) The stress-strain curves and failure characteristics of BRCSs under uniaxial compression could be simulated by dividing the sample unit grids into elements measuring more than $5 \mathrm{~mm}$ and controlling the loading rate to within $0.001 \mathrm{~mm} / \mathrm{step}$

(2) Both experiments and simulations show that the stress-time curve of the BRCSs under true triaxial loading and unloading can be divided into three distinct phases of "elasticity-yield-failure": in the elastic phase, the unloading lateral stress decreases gradually, and the loading lateral stress increases with a certain slope. In the yield phase, due to the fracture and expansion of the coal body, the rate of increase of the applied lateral stress and the rate of reduction of the unloading of lateral stress decrease, resulting in a well-defined yield point; in the failure phase, the applied lateral stress decreases, and stress changes in other directions are small 
(3) Both experiments and simulations show that the peak stress of the BRCSs increases linearly with the increase of the initial stress and has a negative exponential relationship with the RURLRs under true triaxial loading and unloading conditions; thus, the peak stress equations of the BRCSs under true triaxial loading and unloading can be established

(4) Velocity tomographic imaging can reveal the fracture evolution in BRCSs under true triaxial loading and unloading conditions: when the BRCS is subjected to a triaxial stress regime, the high- and lowvelocity regions exist alternately due to the presence of the crack; during the elastic phase, the crack closes under load in the previous phase reopened upon unloading, so that the wave velocity through the specimen decreases and a wide range of low-velocity regions can be formed; when entering the yield phase, the original crack continues to expand into a hole-through crack, leading to a wider range between extreme values and that between the low and highvelocity regions; in the breaking phase, many microcracks are generated again around the holethrough cracks, thereby decreasing the overall wave velocity, and showing the point distribution characteristics of high- and low-velocity regions. Throughout the tests, many low-velocity regions with a similar normal direction to the direction of stress-unloading are formed, which are found to correlate well with macrofractures in postfailure specimens.

\section{Data Availability}

The data used to support the findings of this study are included within the article.

\section{Conflicts of Interest}

The authors declare no conflicts of interest.

\section{Acknowledgments}

The authors extend special thanks to the team at Hua-ting coal mine, who provided the coal body. The authors gratefully acknowledge support by the Key Laboratory of Rock Mechanics and Geohazards of Zhejiang Province (Grant No. ZJRMG-2019-06), the Science and Technology Projects of Jiangsu Construction System (Grant No. 2019ZD001159), the Research Fund of the Jiangsu Engineering Laboratory of Mine Earthquake Monitoring and Prevention, CUMT, and the National Natural Science Foundation of China (Grant No. 51974302).

\section{References}

[1] A. T. Iannacchione and S. C. Tadolini, "Occurrence, predication, and control of coal burst events in the U.S." International Journal of Mining Science and Technology, vol. 26, no. 1, pp. 39-46, 2016.
[2] C. Mark and M. Gauna, "Evaluating the risk of coal bursts in underground coal mines," International Journal of Mining Science and Technology, vol. 26, no. 1, pp. 47-52, 2016.

[3] G.-A. Zhu, L.-M. Dou, C.-B. Wang, J. Li, W. Cai, and Z. W. Dong, "Numerical investigations on evolution characteristics of overlying strata and distribution of static and dynamic load in an island coal panel," Arabian Journal of Geosciences, vol. 10, no. 24, pp. 1-22, 2017.

[4] Z.-L. Li, L.-M. Dou, G.-F. Wang, W. Cai, J. He, and Y.-1. Ding, "Risk evaluation of rock burst through theory of static and dynamic stresses superposition," Journal of Central South University, vol. 22, no. 2, pp. 676-683, 2015.

[5] K. Joanna, K. Jerzy, and N. Roman, "The basic assumptions of the quantitative version of the comprehensive method of rock burst hazard evaluation," Gospodarka Surowcami Mineralnymi-mineral. Resources Management, vol. 29, no. 2, pp. 193-204, 2013.

[6] R. Patynska, "The consequences of the rock burst hazard in the Silesian companies in Poland," Acta Geodynamica et Geomaterialia, vol. 10, no. 2, pp. 227-235, 2013.

[7] L. Dou, T. Chen, S. Gong, H. He, and S. Zhang, "Rockburst hazard determination by using computed tomography technology in deep workface," Safety Science, vol. 50, no. 4, pp. 736-740, 2012.

[8] B. Dai, G. Zhao, H. Konietzky, and P. L. P. Wasantha, "Experimental and numerical study on the damage evolution behaviour of granitic rock during Loading and unloading," KSCE Journal of Civil Engineering, vol. 22, no. 9, pp. 3278-3291, 2018.

[9] G.-Z. Yin, Y.-B. Liu, M.-H. Li, B. Ding, C. Liu, and J. Lu, "Influence of true triaxial loading-unloading stress paths on mechanical property and permeability of coal," Journal of China Coal Society, vol. 43, no. 1, pp. 131-136, 2018.

[10] Q. Bai, M. Tibbo, M. H. B. Nasseri, and R. P. Young, "True triaxial experimental investigation of rock response around the mine-by tunnel under an in situ 3D stress path," Rock Mechanics and Rock Engineering, vol. 52, no. 10, pp. 39713986, 2019.

[11] H.-P. Xie, Z.-T. Zhang, F. Gao, Z. Ru, M. Z. Gao, and J. F. Liu, "Stress-fracture-seepage field behavior of coal under different mining layouts," Journal of China Coal Society, vol. 41, no. 10, pp. 2405-2417, 2016.

[12] K. Du, X.-B. Li, D.-Y. Li, and L. Weng, "Failure properties of rocks in true triaxial unloading compressive test," Transactions of Nonferrous Metals Society of China, vol. 25, no. 2, pp. 571-581, 2015.

[13] G. Su, J. Jiang, S. Zhai, and G. Zhang, "Influence of tunnel Axis stress on strainburst: an experimental study," Rock Mechanics and Rock Engineering, vol. 50, no. 6, pp. 1551-1567, 2017.

[14] D. Li, Z. Sun, T. Xie, X. Li, and P. G. Ranjith, "Energy evolution characteristics of hard rock during triaxial failure with different loading and unloading paths," Engineering Geology, vol. 228, pp. 270-281, 2017.

[15] Z. Chen, G. Su, J. W. Ju, and J. Jiang, "Experimental study on energy dissipation of fragments during rockburst," Bulletin of Engineering Geology and the Environment, vol. 78, no. 7, pp. 5369-5386, 2019.

[16] X. G. Zhao, J. Wang, M. Cai et al., "Influence of unloading rate on the strainburst characteristics of beishan granite under true-triaxial unloading conditions," Rock Mechanics and Rock Engineering, vol. 47, no. 2, pp. 467-483, 2014.

[17] G.-Z. Yin, B. Ma, C. Liu, M. Li, and J. Lu, "Effect of loading and unloading rates on mechanical properties and energy characteristics of sandstone under true triaxial stress," Journal of China Coal Society, vol. 44, no. 2, pp. 454-462, 2019. 
[18] J.-J. Wang, M.-N. Liu, F.-X. Jian, and H. J. Sai, "Mechanical behaviors of a sandstone and mudstone under loading and unloading conditions," Environmental Earth Sciences, vol. 78, no. 30, pp. 1-15, 2019.

[19] X.-T. Feng, R. Kong, X. Zhang, and C. Yang, "Experimental study of failure differences in hard rock under true triaxial compression," Rock Mechanics and Rock Engineering, vol. 52, no. 7, pp. 2109-2122, 2019.

[20] Y. Liu, G. Yin, M. Li et al., "Anisotropic mechanical properties and the permeability evolution of cubic coal under true triaxial stress paths," Rock Mechanics and Rock Engineering, vol. 52, no. 8, pp. 2505-2521, 2019.

[21] G.-a. Zhu, L.-m. Dou, C.-b. Wang, Z.-w. Ding, Z.-j. Feng, and F. Xue, "Experimental study of rock burst in coal samples under overstress and true-triaxial unloading through passive velocity tomography," Safety Science, vol. 117, pp. 388-403, 2019.

[22] H.-G. Zhao, Z.-L. Song, D.-M. Zhang, C. Liu, and B. Yu, “True triaxial experimental study on mechanical characteristics and energy evolution of sandstone under various loading and unloading rates," Geomechanics and Geophysics for Geo-Energy and Geo-Resources, vol. 22, no. 7, pp. 1-17, 2021.

[23] Y. Yang, "Acoustic emission characteristics of coal under different triaxial unloading conditions," Acta Geodynamica et Geomaterialia, vol. 17, no. 1, pp. 51-60, 2020.

[24] Y. Zhang, Y. Yang, and D. Ma, "Mechanical characteristics of coal samples under triaxial unloading pressure with different test paths," Shock and Vibration, vol. 2020, Article ID 8870821, 10 pages, 2020.

[25] X. Si and F. Gong, "Strength-weakening effect and sheartension failure mode transformation mechanism of rockburst for fine-grained granite under triaxial unloading compression," International Journal of Rock Mechanics and Mining Sciences, vol. 131, Article ID 104347, 2020.

[26] F. Stoeckhert, M. Molenda, S. Brenne, and M. Alber, "Fracture propagation in sandstone and slate - laboratory experiments, acoustic emissions and fracture mechanics," Journal of Rock Mechanics and Geotechnical Engineering, vol. 7, no. 3, pp. 237-249, 2015.

[27] J. Guo, G.-R. Feng, T.-Y. Qi et al., "Dynamic mechanical behavior of dry and water saturated igneous rock with acoustic emission monitoring," Shock and Vibration, vol. 2018, Article ID 2348394, 14 pages, 2018.

[28] X.-X. Liu, S.-B. Zhan, Y.-B. Zhang, X. Wang, Z. Z. Liang, and B. Tian, "The mechanical and fracturing of rockburst in tunnel and its acoustic emission characteristics," Shock and Vibration, vol. 2018, Article ID 3503940, 11 pages, 2018.

[29] S.-F. Roohollah and T. Abbas, "Long-term prediction of rockburst hazard in deep underground openings using three robust data mining techniques," Engineering with Computers, vol. 35, no. 2, pp. 659-675, 2018.

[30] M.-C. He, J.-Y. Li, F.-Q. Ren, and D. Q. Liu, "Experimental investigation on rockburst ejection velocity of unidirectional double-face unloading of sandstone with different bedding angles," Chinese Journal of Rock Mechanics and Engineering, vol. 40, no. 3, pp. 433-447, 2021.

[31] A. Cao, C. Wang, G. Jing, W. Cai, G. Zhu, and J. Li, "Passive velocity tomography for mudstone under uniaxial compression using acoustic emission," Geosciences Journal, vol. 21, no. 1, pp. 93-109, 2017.

[32] S. D. Goodfellow, N. Tisato, M. Ghofranitabari, M. H. B. Nasseri, and R. P. Young, "Attenuation properties of fontainebleau sandstone during true-triaxial deformation using active and passive ultrasonics," Rock Mechanics and Rock Engineering, vol. 48, no. 6, pp. 2551-2566, 2015.
[33] D. Duan, Y.-S. Zhao, X.-J. Feng, and X. J. Dang, "Mudstone mesoscopic failure process and generation mechanism of acoustic emission events based on real-time loading CT scan," Journal of China University of Mining \& Technology, vol. 44, no. 1, pp. 29-35, 2015.

[34] D. Li, F. Zhao, and M. Zheng, "Fractal characteristics of cracks and fragments generated in unloading rockburst tests," International Journal of Mining Science and Technology, vol. 24, no. 6, pp. 819-823, 2014.

[35] J. He, L.-M. Dou, W. Cai, Z.- L. Lei, and Y.-L. Ding, "In situ test study of characteristics of coal mining dynamic load," Shock and Vibration, vol. 2015, Article ID 121053, 2015.

[36] N. Hosseini, K. Oraee, K. Shahriar, and K. Goshtasbi, "Passive seismic velocity tomography on longwall mining panel based on simultaneous iterative reconstructive technique (SIRT)," Journal of Central South University, vol. 19, no. 8, pp. 22972306, 2012.

[37] N. Hosseini, K. Oraee, K. Shahriar, and K. Goshtasbi, "Studying the stress redistribution around the longwall mining panel using passive seismic velocity tomography and geostatistical estimation," Arabian Journal of Geosciences, vol. 6, no. 5, pp. 1407-1416, 2013. 